\title{
The present day potential role of fractional flow reserve-guided coronary artery bypass graft surgery
}

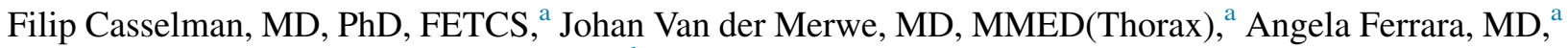
and Emanuele Barbato, MD, PhD, FESC ${ }^{a, b}$

\begin{abstract}
The favorable impact of fractional flow reserve measurements on the decisionmaking and overall outcomes of percutaneous coronary artery intervention is well established. However, the clinical application of fractional flow reserve in surgical revascularizations is still debated. The purpose of this article is to provide a comprehensive review on the current potential role of fractional flow reserve guidance in coronary artery bypass grafting. ( $\mathrm{J}$ Thorac Cardiovasc Surg 2016;151:926-32)
\end{abstract}

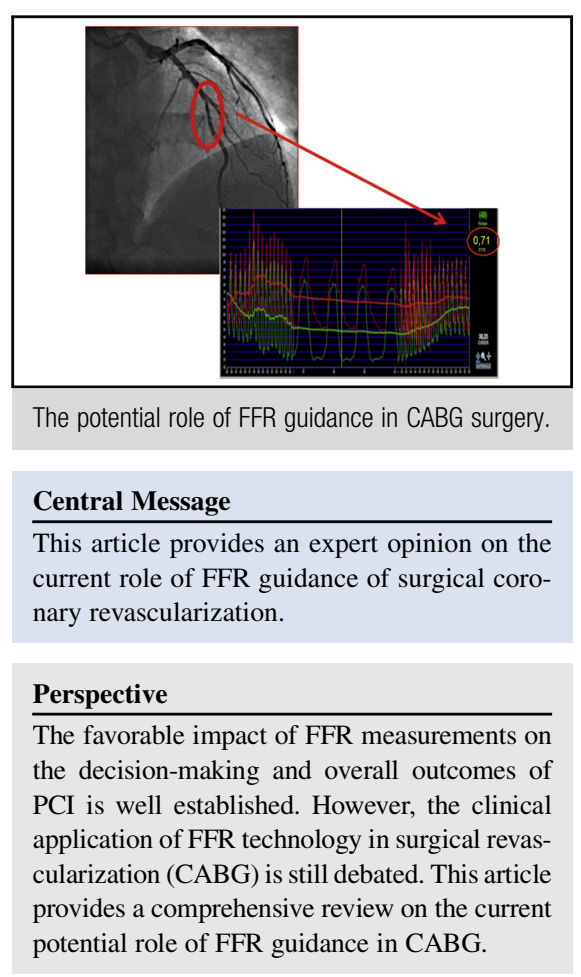

See Editorial Commentary page 933.
The diagnosis and treatment strategies for coronary artery disease traditionally are based on the visual assessment of the coronary stenosis severity observed in multiple angiographic views. We are witnessing a gradual transition from pure anatomic evaluation of individual coronary artery lesions toward determining their physiologic effect on viable myocardium. For both coronary artery bypass grafting $(\mathrm{CABG})$ and percutaneous coronary intervention (PCI), the traditional term "anatomically complete revascularization" is being replaced by "physiologically

From the ${ }^{\mathrm{a} C a r d i o v}$ ascular Center Aalst, OLV Clinic, Aalst, Belgium; and ${ }^{\mathrm{b}}$ Division of Cardiology, Department of Advanced Biomedical Sciences, Federico II University of Naples, Naples, Italy.

Received for publication June 18, 2015; revisions received Sept 7, 2015; accepted for publication Dec 12, 2015; available ahead of print Jan 22, 2016.

Address for reprints: Filip Casselman, MD, PhD, FETCS, Cardiovascular Center Aalst, OLV Clinic, Moorselbaan 164, 9300 Aalst, Belgium (E-mail: filip. casselman@olvz-aalst.be).

$0022-5223 / \$ 36.00$

Copyright (c) 2016 by The American Association for Thoracic Surgery

http://dx.doi.org/10.1016/j.jtcvs.2015.12.021 complete revascularization." Fractional flow reserve (FFR) has emerged as the standard of reference to assess the functional impact of an angiographically visible stenosis on the subtended myocardial territory. FFR has been defined as the ratio of maximal myocardial blood flow in the presence of the stenosis divided by the theoretically normal maximal myocardial blood flow in the absence of the stenosis. ${ }^{1-3}$ FFR informs the operator to what extent the presence of the stenosis limits maximum flow and, thus, to what extent the restoration of the epicardial conductance will increase myocardial perfusion. FFR can uniquely quantify epicardial obstruction that is limiting hyperemic flow and predicts to what extent it is correctable by revascularization.

Scanning this QR code will take you to the article title page. 


\section{Abbreviations and Acronyms \\ $\mathrm{CABG}=$ coronary artery bypass grafting \\ $\mathrm{FFR}=$ fractional flow reserve \\ PCI = percutaneous coronary intervention}

\section{FRACTIONAL FLOW RESERVE MEASUREMENT}

Detailed technical descriptions of how FFR is measured have been reported. ${ }^{3,4}$ The procedure is usually part of the routine diagnostic cardiac catheterization performed with local anesthesia of the puncture site (radial or femoral access). A pressure guide wire has a pressure transducer designed to record the coronary arterial pressure distal to the coronary lesion. The pressure transducer is fluoroscopically visible, and once in position, a hyperemic stimulus is administered by vasodilator injection through the guiding catheter. The mean arterial pressures from the pressure wire transducer and the guide catheter are then used to calculate FFR. FFR is defined as the ratio of the average distal coronary pressure to average aortic pressure at maximal steady state hyperemia. The latter is commonly obtained with the administration of adenosine intracoronarily or intravenously. ${ }^{5}$

\section{IMPACT OF FRACTIONAL FLOW RESERVE ON PERCUTANEOUS CORONARY INTERVENTION AND REVASCULARIZATION DECISION MAKING}

Various studies and registries have compared traditional CABG and PCI before the general introduction of FFR into clinical practice. Outcome analyses of 189,793 propensity-matched patients in the observational American College of Cardiology Foundation and the Society of Thoracic Surgeons Collaboration on the Comparative Effectiveness of Revascularization Strategies (ASCERT) study concluded that long-term survival in patients aged more than 65 years was better with CABG than with PCI. ${ }^{6}$ The Synergy Between PCI With Taxus and Cardiac Surgery (SYNTAX) trial showed lower rates of major adverse cardiac or cerebrovascular events with CABG than with PCI in patients with 3-vessel or left main coronary artery disease at 1- and 5-year follow-ups and recommended that CABG remains the standard of care for complex lesions calculated by the SYNTAX score. ${ }^{7,8}$ These findings also were observed in diabetic patients with multivessel disease in the Future Revascularization Evaluation in Patients With Diabetes Mellitus: Optimal Management of Multivessel Disease (FREEDOM) trial. ${ }^{9}$ The recently published Trial of Everolimus-Eluting Stents or Bypass Surgery for Coronary Disease (BEST) trial enrolled 880 patients with multivessel coronary artery disease, of whom 438 were randomly assigned to nonFFR-guided PCI with second-generation drug-eluting stents and 442 were assigned to CABG. The investigators observed no significant differences between the 2 groups in the occurrence of a composite safety end point of death, myocardial infarction, or stroke. However, the rates of any repeat revascularization and spontaneous myocardial infarction were significantly higher after PCI than after CABG. $^{10}$

The Deferral Versus Performance of PCI of NonIschemia-Producing Stenosis (DEFER) study was the first randomized trial to investigate the applicability of an FFR-guided PCI in patients with single-vessel disease and intermediate coronary stenosis. ${ }^{11}$ In patients with nonischemic coronary stenoses (ie, with an FFR $>0.75$ ), intervention did not add any benefit to the overall outcomes compared with treating these stenoses conservatively with medical therapy. This study subsequently suggested that FFR is a useful tool to defer nonfunctionally significant coronary stenoses to optimal medical therapy ${ }^{12}$ and posed the basis of an FFR-guided PCI strategy in this setting.

The Fractional Flow Reserve Versus Angiography for Guiding PCI in Patients With Multivessel Coronary Artery Disease (FAME) trial evaluated the role of FFR in patients with multivessel coronary artery disease compared with traditional PCI strategy based only on the angiographic stenosis severity. The FAME trial introduced the concept of physiologic versus anatomic revascularization. ${ }^{13}$ In 20 centers in Europe and the United States, 1005 patients scheduled for a PCI with drug-eluting stents were randomized to angiography-guided or FFR-guided treatment. In the angiography-guided arm of the study, all lesions deemed significant on the basis of their anatomic severity were stented. In the FFR arm, only functionally significant lesions with an FFR less than 0.80 were stented, whereas those with an FFR greater than 0.80 were deferred to medical therapy. The rate of major adverse cardiovascular events at 1 year was significantly reduced by the FFR-guided PCI strategy compared with the angiography-guided strategy. This clinical benefit was mostly driven by a decrease in the need for repeat revascularization in the FFR-guided group in addition to the reduced number of stents used, amount of contrast required, and subsequent lower procedure-related costs. At the prespecified 2-year follow-up analysis of the FAME patients, the incidence of mortality or myocardial infarction was significantly lower in the FFR-guided group. The FAME trial reinforced the results of the DEFER trial in patients with multivessel disease that stenting nonsignificant lesions offers no functional or prognostic clinical benefit and could be associated with increased incidence of in-stent restenosis, thrombosis, and related sequelae. ${ }^{14}$

In the FAME II trial, the combination of PCI plus optimal medical therapy for coronary lesions with an FFR less than 0.80 compared with medical therapy alone significantly decreased the need for urgent revascularization. ${ }^{15}$ Landmark analysis of the FAME II trial demonstrated that beyond 7 days, PCI plus optimal medical therapy was 


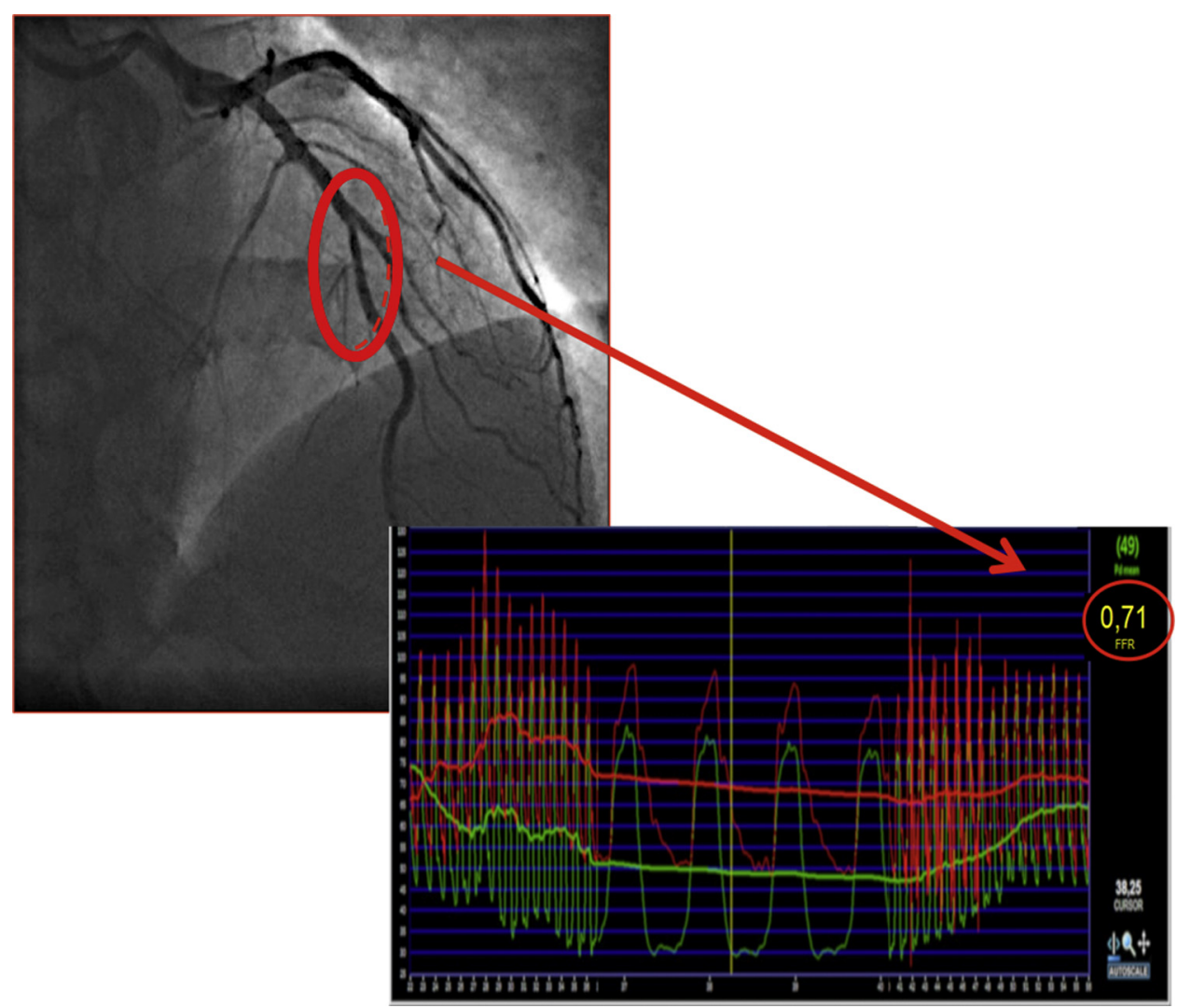

FIGURE 1. Example of nonsignificant angiographic stenosis of the left anterior descending artery (left) revealing a hemodynamic significant lesion (right). Revascularization is indicated.

associated with a $44 \%$ reduction in the relative risk of hard end points, such as death and myocardial infarction. ${ }^{16}$ In those patients with stenosis with an FFR greater than 0.80 , medical therapy alone resulted in excellent outcomes, regardless of the angiographic appearance of the stenosis. FFR also was helpful in determining the significance of angiographic equivocal left main stenosis to decide whether a revascularization procedure was necessary. ${ }^{17}$ These findings were further corroborated by numerous observational studies in the most diverse clinical and angiographic settings that consistently demonstrated a superior clinical outcome when a PCI strategy was guided by FFR assessment. ${ }^{18-20} \mathrm{~A}$ recent large meta-analysis suggested an important prognostic role of FFR demonstrating a continuous and independent relationship with clinical outcomes, confirming that an FFR-guided strategy leads to revascularization approximately half as often as an anatomy-based strategy, but with $20 \%$ fewer adverse events and $10 \%$ better angina relief. ${ }^{21}$ These studies established the premises that percutaneous interventions should be guided by the combination of accurate physiologic and high-quality anatomic information. This paradigm shift posed the basis of a functional reclassification of the extent and severity of coronary artery disease. Recent studies have suggested that a functional SYNTAX score could bear significant prognostic information by computing in the calculation of the score only those coronary lesions with an FFR less than 0.80 . By implementing the functional SYNTAX score, up to $32 \%$ of the studied patients were reclassified from higher- to lower-risk groups and were subsequently considered treatable by both FFR-guided PCI or conventional CABG as opposed to CABG alone. ${ }^{22}$

The much anticipated FAME III study is a randomized multicenter trial designed to demonstrate that FFR-guided PCI with second-generation drug-eluting stent is noninferior to angiographically guided CABG in non-left main multivessel disease that is treatable by both PCI and CABG according to the "heart team decision making." FAME III plans to enroll 1500 patients over 2 years. The trial will be conducted as collaborative effort between 50 international centers and will report on a 5-year clinical follow-up.

The positive clinical benefits demonstrated by DEFER, FAME, and FAME II trials certainly apply to patients undergoing percutaneous revascularizations. Whether these results also might extend to surgical candidates or revascularization strategies is a matter of active and ongoing investigation. These trials excluded typical surgical candidates, such as patients with left main stenosis or valve disease. They mostly included patients with 


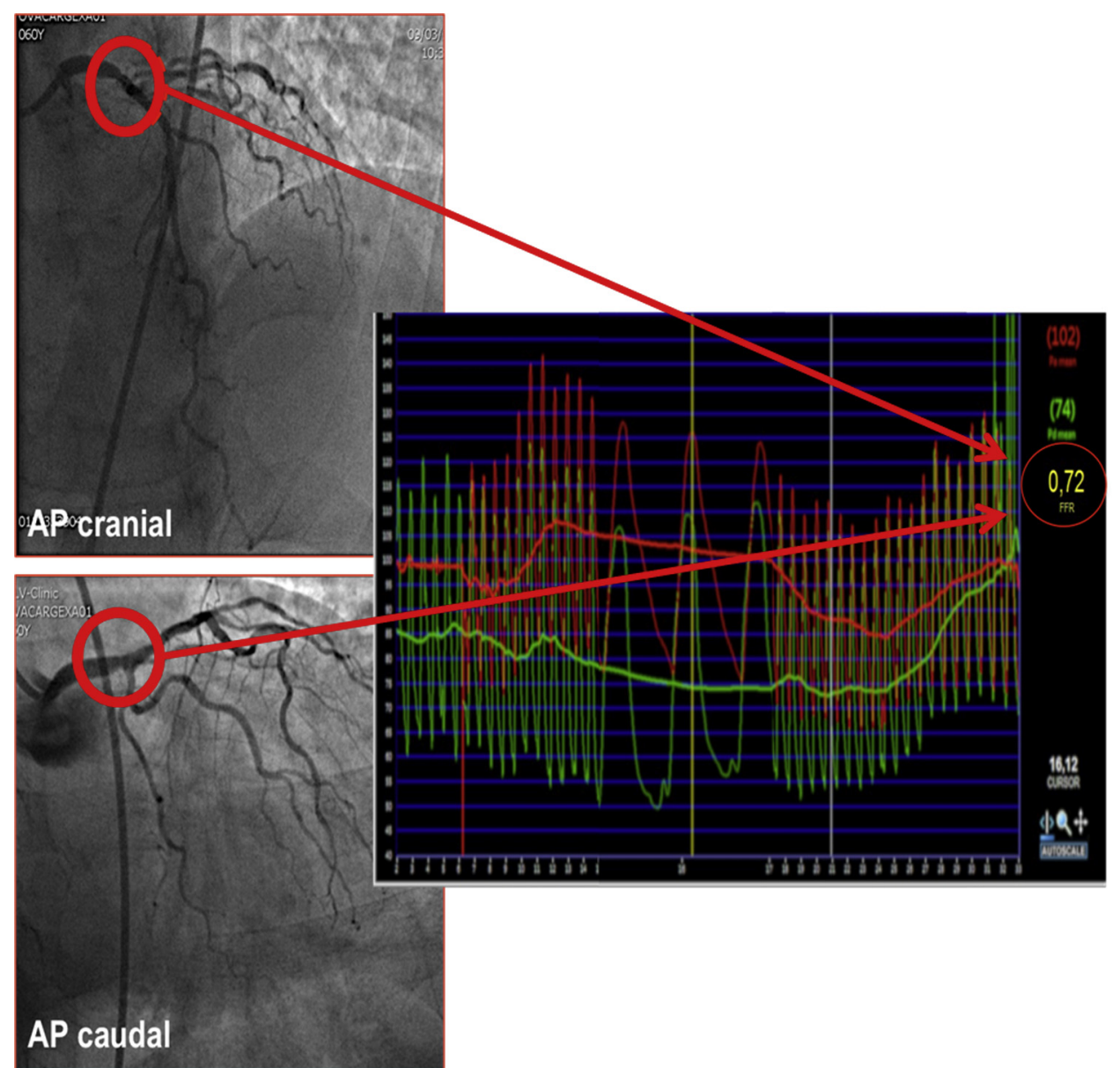

FIGURE 2. Example of an angiographically nonsignificant stenosis of the distal left main coronary artery (left) revealing a hemodynamic significant lesion (right). This lesion requires revascularization. AP, Anteroposterior.

stable coronary artery disease and a variable proportion of patients with single-vessel disease (in DEFER and FAME II trials).

\section{IMPACT OF FRACTIONAL FLOW RESERVE ON CORONARY ARTERY BYPASS GRAFTING}

Botman and coworkers ${ }^{23}$ prospectively studied 1-year bypass grafts patency in 164 patients randomized to FFR-guided or angiography-guided grafting. Graft occlusions were found in $8.9 \%$ of the FFR-guided versus $21.4 \%$ of the angiography-guided patients $(P<.01)$. These findings were observed for both arterial $(13.7 \%$ FFR-guided vs $21.9 \%$ angiography-guided; $P<.2)$ and venous $(5.9 \%$ FFR-guided vs $20.0 \%$ angiography-guided; $P<.03)$ grafts. In those patients with angiographic stenosis of $50 \%$ to $70 \%$, the graft patency was higher if the FFR was less than 0.75 and vessel diameter more than $2.0 \mathrm{~mm}$. However, these findings were of limited clinical significance because patients with occluded grafts on noncritical lesions had no significant increase in angina or need for repeat revascularization.
In the Cardiovascular Center Aalst in Belgium, we sought to determine the impact of FFR on CABG outcomes by retrospectively comparing angiography-guided versus FFR-guided grafting strategies. ${ }^{24}$ In the angiographyguided group, 429 patients were surgically vascularized solely on the basis of the angiographic stenosis severity. The FFR-guided group consisted of 198 patients who underwent bypass grafting of only those stenotic vessels with FFR 0.80 or less, whereas those with FFR greater than 0.80 were deferred to medical therapy. We observed that the incidence of multivessel disease was significantly downgraded in the FFR-guided group, which resulted in a decreased number of grafts applied. Arterial grafts were used in $71 \%$ of the FFR-guided group opposed to $55 \%$ in the angiography-guided group. After 3 years of follow-up, there was no difference in the incidence of major adverse cardiac events (composite of overall death, myocardial infarction, or need for target revascularization) between the 2 groups, but the incidence of severe angina was lower in the patients undergoing FFR-guided CABG $(31 \%$ vs $4 \% ; P<.001)$. In a subgroup of 155 patients $(25 \%)$ who 


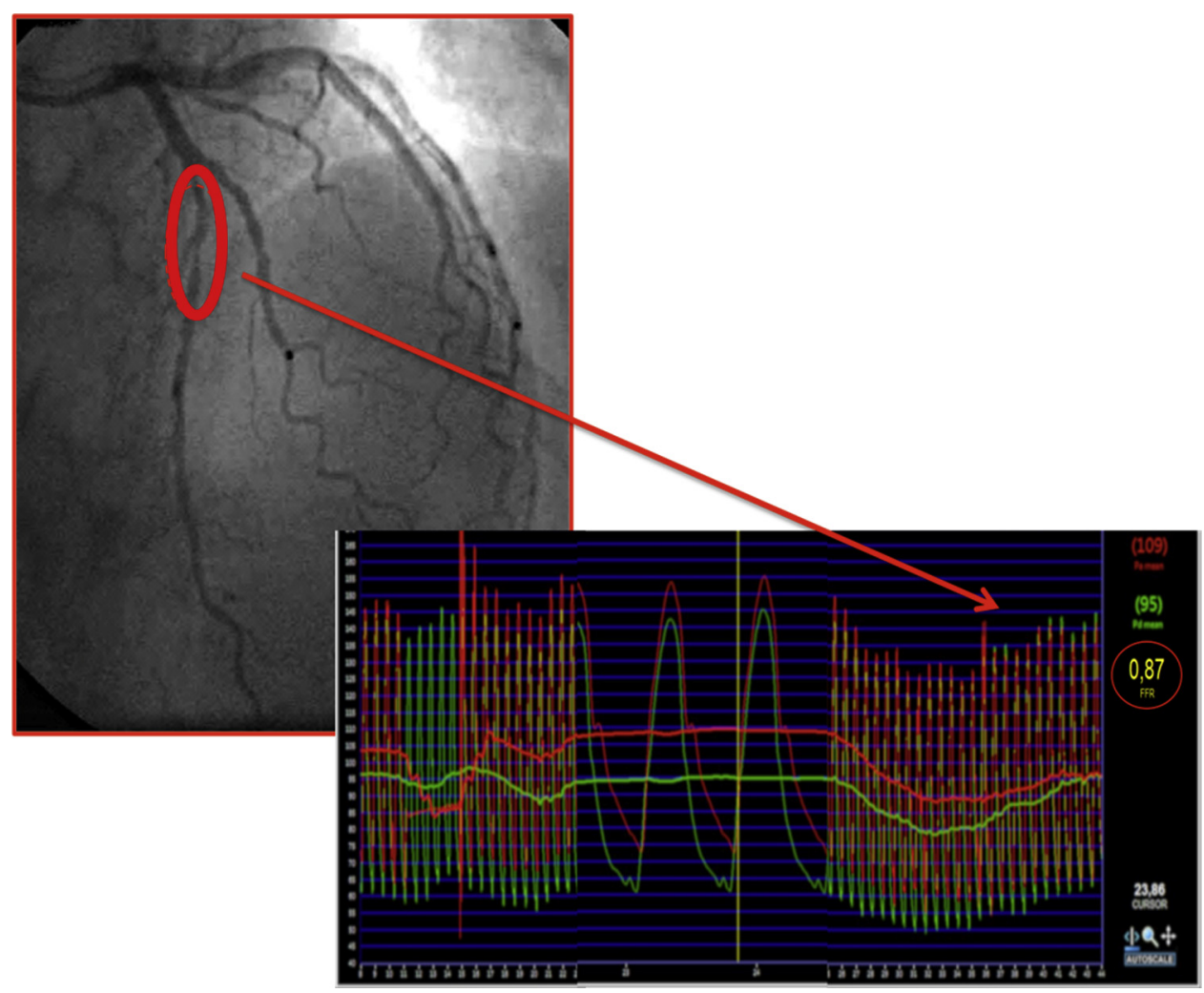

FIGURE 3. Example of significant angiographic stenosis of the left anterior descending artery (left) revealing a hemodynamic nonsignificant lesion (right) with FFR measurement. This lesion should not be revascularized.

underwent repeated coronary angiography for clinical indications, freedom from graft occlusion was higher in the FFR-guided group of patients, confirming and extending up to 3 years the previous findings from Botman and colleagues. ${ }^{23}$ This study suggested the safety of FFR-guided CABG that resulted in a simplified surgical protocol without compromising efficacy, at the advantage of a lower incidence of recurrent angina. Although these findings are interesting, they should be considered hypothesis generating, given the inherent limitations related to retrospective design of the study.

Ferguson and coworkers ${ }^{25}$ used near-red fluorescence angiography with indocyanine green dye bolus injection to detect myocardial regional perfusion response after CABG surgery in an attempt to provide further evidence of the potential disparity between an angiographic significant coronary stenosis and the subsequent physiologic severity. A total of 359 grafts were imaged in 160 patients. All grafts were patent, but $24 \%$ of arterial grafts and $22 \%$ of vein grafts did not change regional perfusion. In 165 left internal thoracic to left anterior descending artery grafts with at least $70 \%$ proximal left anterior descending artery stenosis, $24.2 \%$ had no change in regional myocardial perfusion, of which $80 \%$ presented features of competitive flow.
Apart from technical factors, choice of conduit, and graft and native vessel disease progression as causes of graft failure, FFR-guided surgery may reduce the risk of competitive flow in both single and sequential arterial grafts and when target vessels are less than $1 \mathrm{~mm}$ in diameter. ${ }^{26-28}$

One of the reasons that patients are referred for surgical revascularization rather than $\mathrm{PCI}$ is the concept that CABG offers the patient more complete revascularization. The latter is of major importance considering that it is well accepted that incomplete revascularization is associated with reduced long-term survival.

\section{FRACTIONAL FLOW RESERVE-GUIDED LIMITATIONS IN CORONARY ARTERY BYPASS GRAFTING}

FFR measurements in diffuse, multisegment coronary atherosclerosis and bifurcating lesions might be technically challenging and require some experience, especially in the correct interpretation of the assessment.

We still do not know the long-term effects of leaving ungrafted nonfunctionally significant stenoses because most studies have only short-term follow-up (1-3 years) and include a small number of patients.

FFR-guided PCI addresses the obstructive lesion directly, and therefore the ability of this strategy to relieve segmental 


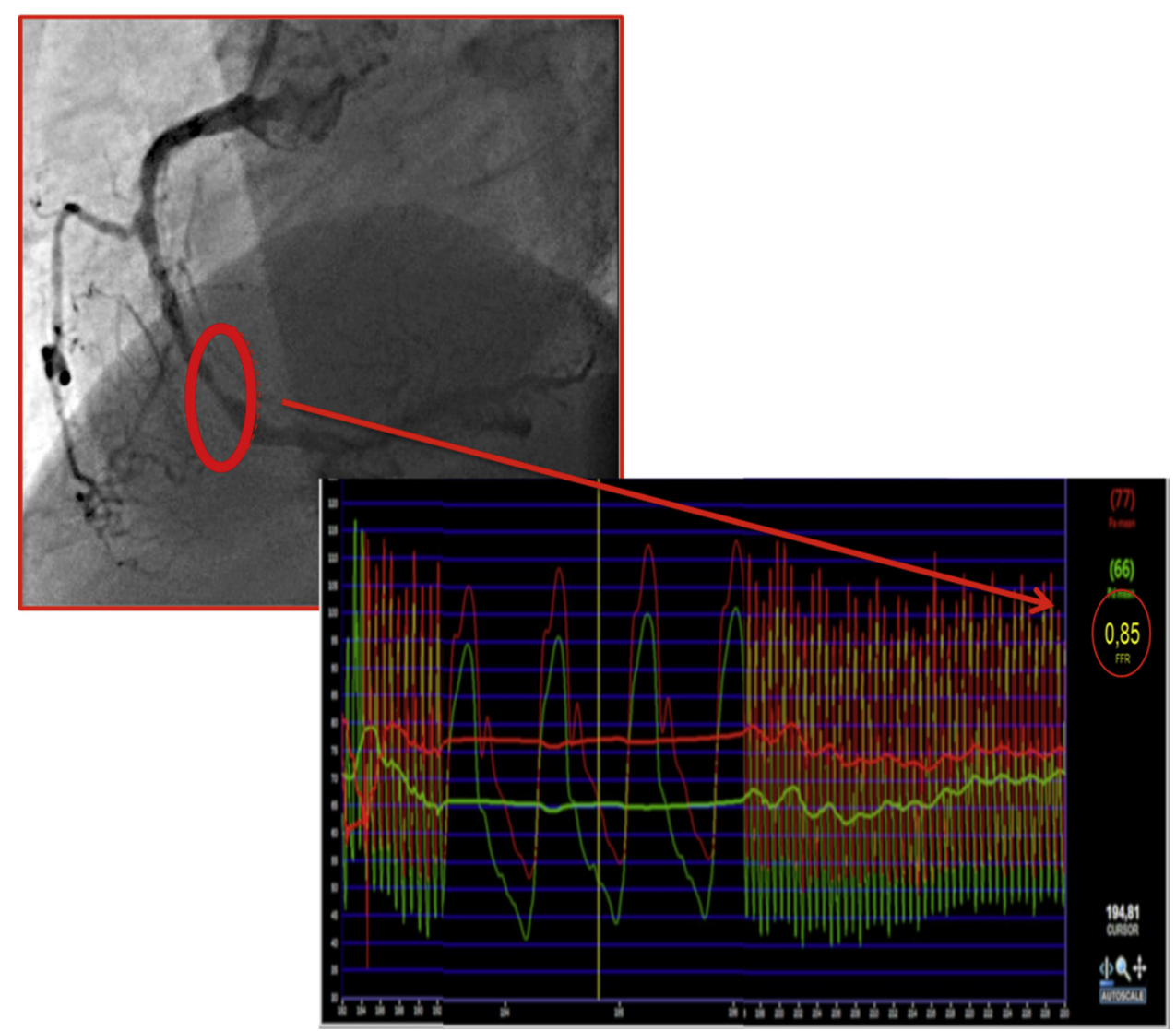

FIGURE 4. Example of significant angiographic stenosis of the right coronary artery (left) revealing a hemodynamic nonsignificant lesion (right). Revascularization may result in adverse graft and patient outcome.

physiologic obstruction is highly relevant. However, CABG addresses the whole vascular bed by supplying directly downstream circulation.

There may be major differences in the manner in which high-flow passive conduits, such as saphenous vein grafts, and physiologically responsive intact nitric oxideproducing grafts, such as the internal thoracic artery, affect the long-term outcome when applied to a vessel that does or does not have physiologically obstructive disease measured by FFR. ${ }^{29}$

\section{CLINICAL EXAMPLES ILLUSTRATING THE DISPARITY BETWEEN ANGIOGRAPHY AND FRACTIONAL FLOW RESERVE LESION EVALUATION}

Figures 1 and 2 illustrate how FFR measurements identified angiographic insignificant coronary artery stenosis as being hemodynamically significant. Revascularization was indicated and performed. Figures 3 and 4 describe how FFR measurements identified angiographically significant coronary lesions as hemodynamically insignificant. Revascularization of these lesions may result in adverse graft patency and patient outcome.

\section{CONCLUSIONS}

FFR-guided $\mathrm{CABG}$ is now under intense investigation and may have an important role in determining whether angiographically intermediate stenoses should be bypassed, whether these lesions have a significant physiologic role on the distal myocardium, and whether these lesions influence long-term graft patency. FFR has proven its worth in PCI decision-making, but before changes are made in determining what vessels should be grafted during CABG, larger prospective randomized trials with longer follow-up are needed to better understand the role of this technology. The graft patency after FFR-guided versus angiography-guided CABG trial (GRAFFITI) is a randomized clinical trial currently in progress to address these questions in the context of the much anticipated FAME III trial results (ClinicalTrials.gov Identifier: NCT01810224).

\section{Conflict of Interest Statement}

E.B. is a consultant to St Jude Medical. All grants and consultancy fees go to the Cardiovascular Research Center, OLV-Clinic, Aalst, Belgium. All other authors have nothing to disclose with regard to commercial support. 
The authors thank Dr Bernard De Bruyne, MD, PhD, for his contribution to the writing of this article.

\section{References}

1. Pijls NH, van Son JA, Kirkeeide RL, De Bruyne B, Gould KL. Experimental basis of determining maximum coronary, myocardial, and collateral blood flow by pressure measurements for assessing functional stenosis severity before and after percutaneous transluminal coronary angioplasty. Circulation. 1993;87:1354-67.

2. De Bruyne B, Baudhuin T, Melin JA, Pijls NH, Sys SU, Bol A, et al. Coronary flow reserve calculated from pressure measurements in humans. Validation with positron emission tomography. Circulation. 1994;89:1013-22.

3. Pijls NH, De Bruyne B, Peels K, Van Der Voort PH, Bonnier HJ, Bartunek J, et al. Measurement of fractional flow reserve to assess the functional severity of coronary-artery stenoses. N Engl J Med. 1996;334:1703-8.

4. Mangiacapra F, Barbato E. From SYNTAX to FAME, a paradigm shift in revascularization strategies: the key role of fractional flow reserve in guiding myocardial revascularization. J Cardiovasc Med. 2011;12:538-42.

5. Barbato E, Sarno G, Berza CT, Di Gioia G, Bartunek J, Vanderheyden M, et al. Impact of alpha- and beta-adrenergic receptor blockers on fractional flow reserve and index of microvascular resistance. J Cardiovasc Transl Res. 2014; 7:803-9.

6. Weintraub WS, Grau-Sepulveda MV, Weiss JM, O'Brien SM, Peterson ED Kolm P, et al. Comparative effectiveness of revascularization strategies. $N$ Engl J Med. 2012;366:1467-76.

7. Serruys PW, Morice MC, Kappetein AP, Colombo A, Holmes DR, Mack MJ, et al; SYNTAX Investigators. Percutaneous coronary intervention versus coronary-artery bypass grafting for severe coronary artery disease. $N$ Engl $J$ Med. 2009;360:961-72.

8. Mohr FW, Morice MC, Kappetein AP, Feldman TE, Ståhle E, Colombo A, et al. Coronary artery bypass graft surgery versus percutaneous coronary intervention in patients with three-vessel disease and left main coronary disease: 5-year follow-up of the randomised, clinical SYNTAX trial. Lancet. 2013;381: 629-38.

9. Farkouh ME, Domanski M, Sleeper LA, Siami FS, Dangas G, Mack M, et al; FREEDOM Trial Investigators. Strategies for multivessel revascularization in patients with diabetes. N Engl J Med. 2012;367:2375-84.

10. Park SJ, Ahn JM, Kim YH, Park DW, Yun SC, Lee JY, et al; BEST Trial Investigators. Trial of everolimus-eluting stents or bypass surgery for coronary disease. N Engl J Med. 2015;372:1204-12.

11. Pijls NH, van Schaardenburgh P, Manoharan G, Boersma E, Bech JW, van't Veer M, et al. Percutaneous coronary intervention of functionally nonsignificant stenosis: 5-year follow- up of the DEFER Study. J Am Coll Cardiol. 2007;49:2105-11.

12. Lembo G, Morisco C, Lanni F, Barbato E, Vecchione C, Fratta L, et al. Systemic hypertension and coronary artery disease: the link. Am J Cardiol. 1998;82:2H-7H.

13. Tonino PA, De Bruyne B, Pijls NH, Siebert V, Ikeno F, van't Veer M, et al. Fractional flow reserve vs. angiography for guiding percutaneous coronary intervention. N Engl J Med. 2009;360:213-24.

14. Pijls NH, Fearon WF, Tonino PAO, Siebert U, Ikeno F, Bornschein B, et al Fractional flow reserve vs. angiography for guiding percutaneous coronary intervention in patients with multivessel coronary artery disease. J Am Coll Cardiol. 2010;56:177-84.

15. De Bruyne B, Pijls NH, Kalesan B, Barbato E, Tonino PA, Piroth Z, et al; FAME 2 Trial Investigators. Fractional flow reserve-guided PCI versus medical therapy in stable coronary disease. N Engl J Med. 2012;367:991-1001.
16. De Bruyne B, Fearon WF, Pijls NH, Barbato E, Tonino P, Piroth Z, et al; FAME 2 Trial Investigators. Fractional flow reserve-guided PCI for stable coronary artery disease. N Engl J Med. 2014;371:1208-17.

17. Hamilos M, Muller O, Cuisset T, Ntalianis A, Chlouverakis G, Sarno G, et al. Long-term clinical outcome after fractional flow reserve-guided treatment in patients with angiographically equivocal left main coronary artery stenosis. Circulation. 2009;120:1505-12.

18. Muller O, Mangiacapra F, Ntalianis A, Verhamme KM, Trana C, Hamilos M, et al. Long-term follow-up after fractional flow reserve-guided treatment strategy in patients with an isolated proximal left anterior descending coronary artery stenosis. JACC Cardiovasc Interv. 2011;4:1175-82.

19. Puymirat E, Peace A, Mangiacapra F, Conte M, Ntarladimas Y, Bartunek J, et al. Long-term clinical outcome after fractional flow reserve-guided percutaneous coronary revascularization in patients with small-vessel disease. Circ Cardiovasc Interv. 2012;5:62-8.

20. Di Serafino L, De Bruyne B, Mangiacapra F, Bartunek J, Agostoni P, Vanderheyden $\mathrm{M}$, et al. Long-term clinical outcome after fractional flow reserve- versus angio-guided percutaneous coronary intervention in patients with intermediate stenosis of coronary artery bypass grafts. Am Heart J. 2013; $166: 110-8$.

21. Johnson NP, Tóth GG, Lai D, Zhu H, Açar G, Agostoni P, et al. Prognostic value of fractional flow reserve: linking physiologic severity to clinical outcomes. JAm Coll Cardiol. 2014;64:1641-54.

22. Nam CW, Mangiacapra F, Entjes R, Chung IS, Sels JW, Tonino PA, et al; FAME Study Investigators. Functional SYNTAX score for risk assessment in multivessel coronary artery disease. J Am Coll Cardiol. 2011;58: 1211-8.

23. Botman CJ, Schonberger J, Koolen S, Penn O, Botman H, Dib N, et al. Does stenosis severity of native vessels influence bypass graft patency? A prospective fractional flow reserve-guided study. Ann Thorac Surg. 2007;83: 2093-7.

24. Toth G, De Bruyne B, Casselman F, De Vroey F, Pyxaras S, Di Serafino L, et al. Fractional flow reserve-guided versus angiography-guided coronary artery bypass graft surgery. Circulation. 2013;128:1405-11.

25. Ferguson TB, Chen C, Babb JD, Efird JD, Daggubati R, Cahill JM. Fractional flow reserve-guided coronary artery bypass grafting: can intraoperative physiological imaging guide decision-making? J Thorac Cardiovasc Surg. 2013;145:1-12.

26. Sabik JF III, Lytle BW, Blackstone EH, Khan M, Houghtaling PL, Cosgrove DM. Does competitive flow reduce internal thoracic artery graft patency? Ann Thorac Surg. 2003;76:1490-6.

27. Berger A, MacCarthy PA, Siebert U, Carlier S, Wijns W, Heyndrickx G, et al. Long-term patency of internal mammary artery bypass grafts: relationship with preoperative severity of the native coronary artery stenosis. Circulation. 2004; 110(suppl 1):II36-40.

28. Gaudino M, Alessandrini F, Pragliola C, Cellini C, Glieca F, Luciani N, et al. Effect of target artery location and severity of stenosis on mid-term patency of aorta-anastomosed vs. internal thoracic artery-anastomosed radial artery grafts. Eur J Cardiothorac Surg. 2004;25:424-8.

29. Gersh BJ, Frye RL. Methods of coronary revascularization-things may not be as they seem. N Engl J Med. 2005;352:2235-7.

Key Words: coronary artery bypass grafting, fractional flow reserve, outcomes, percutaneous coronary intervention 